\title{
New mechanistic insights into the lignin $\beta-O-4$ linkage acidolysis with ethylene glycol stabilization aided by multilevel computational chemistry
}

\author{
Alessandra De Santi ${ }^{* \pi}$, Susanna Monti ${ }^{* *}$, Giovanni Barcaro", Zhenlei Zhangף, Katalin Barta ${ }^{\dagger *}$,
} Peter J. Deuss ${ }^{\top *}$

†Stratingh Institute for Chemistry, University of Groningen, Nijenborgh 4, Groningen, The Netherlands ${ }^{\$}$ CNR-ICCOM- Institute of Chemistry of Organometallic Compounds, via Moruzzi 1, 56124 Pisa, Italy ${ }^{\#}$ CNR-IPCF-Institute for Chemical and Physical Processes, via Moruzzi 1, 56124 Pisa, Italy 'Department of Chemical Engineering (ENTEG), University of Groningen, Nijenborgh 4, Groningen, The Netherlands

vDepartment of Chemistry, Organic and Bioorganic Chemistry, University of Graz, Heinrichstrasse 28/II, 8010 Graz, Austria

*Correspondence to: sapeptides@gmail.com; p.j.deuss@rug.nl; katalin.barta@uni-graz.at

Total number of pages: 13

Total number of Figures: 6 (Figures S1-S6)

Total number of Tables: 1 (Tables S1) 


\section{Table of Contents}

Material \& Methods. Synthesis of lignin $\beta-\mathrm{O}-4$ model compounds 1-G and 1-S. Gaschromatography analysis (GC-FID and GC-MS). High-Performance liquid chromatography analysis (HPLC). Computational details

Figure S1. Representative configuration extracted from the molecular dynamics simulations of 1$\mathrm{G}$ in a DMC solution containing $\mathrm{H}_{2} \mathrm{SO}_{4}$ and $\mathrm{EG}$ molecules. a) Simulation box showing isolated and clustered solute structures surrounded by the catalyst and stabilizer molecule s. b) Extracted subset where one 1-G molecule is in contact with one molecule of the catalyst and one molecule of the stabilizer and is surrounded by 50 solvent molecules. S, O, C, H atoms are yellow, red, grey and cyan, respectively.

Figure S2. Representative configuration extracted from the molecular dynamics simulations of 1$\mathrm{G}$ in a DMC solution containing $\mathrm{H}_{2} \mathrm{SO}_{4}$ and $\mathrm{EG}$ molecules showing two solute molecules with perpendicular orientations of the rings. S, O, C, H atoms are yellow, red, grey and cyan,

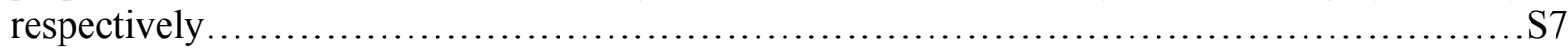

Figure S3. Minimum energy path and molecular structures of the reaction mechanisms depicting the formation of $3-\mathrm{G}$ from $4-\mathrm{G}$.

Figure S4. Minimum energy path and molecular structures of the reaction mechanisms depicting a) the formation of an intermediate 10-G starting from $6-G$ and EG; b) the formation of 7-G and water starting from $10-\mathrm{G}$ .S8

Figure S5. a) Minimum energy path and molecular structures of the reaction mechanism depicting the formation of 4-G from 1-G .b) Superimposed molecular configurations sampled along the reaction pathway obtained with the NEB approach.

Figure S6. Acidolysis reaction profiles of a) 1-G no EG (path 1; b) 1-G with EG (path 2); c) 1-S no EG (path 1); d) 1-S in path 2 (with EG) as determined by HPLC/GC(FID) using 2 mol\% sulfuric acid instead of $5 \mathrm{~mol} \%$ S10

Table S1. Acidolysis reaction of model compound $1-\mathrm{G}$ and $1-\mathrm{S}$ using $\mathrm{HCl}$ as catalyst.........S11 


\section{MATERIALS AND METHODS}

\section{1-G and 1-S synthesis}

1-G and 1-S were prepared as previously reported. ${ }^{1}$

1-G:

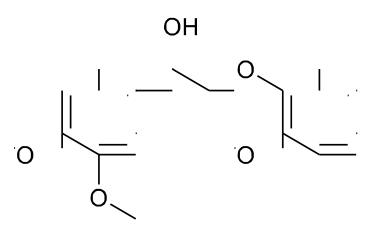

${ }^{1}$ H NMR (600 MHz, CDCl $) \delta 7.03-6.98(\mathrm{~m}, 2 \mathrm{H}), 6.98-6.89(\mathrm{~m}, 4 \mathrm{H}), 6.86(\mathrm{~d}, J=8.2 \mathrm{~Hz}, 1 \mathrm{H})$, $5.05(\mathrm{dd}, J=9.4,2.9 \mathrm{~Hz}, 1 \mathrm{H}), 4.17(\mathrm{dd}, J=10.1,2.9 \mathrm{~Hz}, 1 \mathrm{H}), 3.97$ (t, $J=9.7 \mathrm{~Hz}, 1 \mathrm{H}), 3.90$ (s, 3H), 3.89 (s, 3H), 3.88 (s, 3H). ${ }^{13} \mathbf{C}$ NMR (151 MHz, CDCl 3 ) $\delta 150.20,149.10,148.78,147.99$, 132.11, 122.62, 121.10, 118.63, 116.16, 111.99, 111.03, 109.37, 76.45, 72.13, 55.96, 55.90, 55.86. Spectral data are in accordance with those previously reported ${ }^{1,2}$ HRMS (ESI+) calculated for $\mathrm{C}_{17} \mathrm{H}_{20} \mathrm{O}_{5} \mathrm{Na}:[\mathrm{M}+\mathrm{Na}]^{+}$327.12029, found 327.12087.

\section{1-S:}

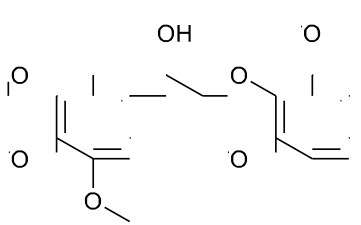

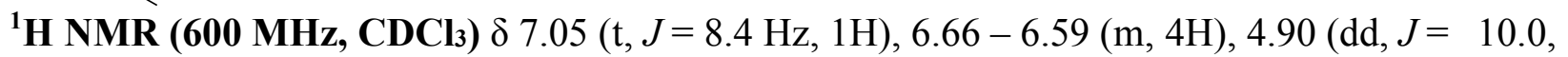
$2.6 \mathrm{~Hz}, 1 \mathrm{H}), 4.42(\mathrm{dd}, J=11.0,2.6 \mathrm{~Hz}, 1 \mathrm{H}), 3.89(\mathrm{~s}, 6 \mathrm{H}), 3.86(\mathrm{~s}, 6 \mathrm{H}), 3.82(\mathrm{~s}, 3 \mathrm{H}), 3.693 .69(\mathrm{t}$, $J=10.4 \mathrm{~Hz}, 1 \mathrm{H}) .{ }^{13} \mathbf{C}$ NMR $\left(\mathbf{1 5 1} \mathbf{~ M H z}, \mathbf{C D C l}_{3}\right) \delta 153.25,137.36,136.83,135.08,124.15,105.15$, 103.22, 80.21, 72.61, 60.82, 56.13, 56.12. HRMS (ESI+) calculated for $\mathrm{C}_{19} \mathrm{H}_{24} \mathrm{O}_{7} \mathrm{Na}:[\mathrm{M}+\mathrm{Na}]^{+}$ 387.14142 , found 387.14188 .

Gas chromatography (FID or MS) analysis. GC-FID analysis was performed using a Shimadzu GC-2014 equipped with a FID detector using helium as a carrier gas. Standard settings: $1 \mu \mathrm{L}$ injection $\left(300^{\circ} \mathrm{C}\right)$, split ratio $50: 1$, helium flow $0.95 \mathrm{~mL} \cdot \mathrm{min}^{-1}$. The $\mathrm{GC}$ apparatus was equipped with an HP5 column $(30 \mathrm{~m} \times 0.25 \mathrm{~mm} \times 0.25 \mu \mathrm{m})$. The following temperature profile was used: 5 min $60{ }^{\circ} \mathrm{C}$ isotherm followed by a $10 \mathrm{C} \cdot \mathrm{min}^{-1}$ ramp for 20 minutes to $260^{\circ} \mathrm{C}$, which was kept for 7 minutes. Then, the temperature was increased to $300{ }^{\circ} \mathrm{C}$ by a $10 \mathrm{C} \cdot \mathrm{min}^{-1} \mathrm{ramp}$ in 5 minutes and maintained for 7 minutes. The detector temperature was $300{ }^{\circ} \mathrm{C}$. GC-FID analysis was used to quantify 7-G, 5-G/5-S and 1-G according to the calibration versus 1,2,4,5 tetramethylbenzene (internal standard) and 7-S, 4-G and 4-S, 3-G and 3-S according to effective carbon number method (ECN, validated using the compounds available for calibration). GC-MS analysis was performed using Shimadzu GC-MS equipped with an HP5 column (30 m x $0.25 \mathrm{~mm} \times 0.25 \mu \mathrm{m})$ using the same method as described for GC-FID for identification purposes.

High-Performance liquid chromatography analysis (HPLC). HPLC analysis was performed using an Agilent Eclipse XDB-C18 5 Column (5 $\mu \mathrm{m}, 4.6 \times 150 \mathrm{~mm})$. All samples were analyzed using a $\mathrm{MeCN}$ (0.1 vol \% trifluoroacetic acid) (A)/ $\mathrm{H}_{2} \mathrm{O}(0.1 \mathrm{vol} \%$ trifluoroacetic acid) (B) gradient follow with a flow rate of $1.0 \mathrm{~mL} \cdot \min -1$. HPLC Method: $5 \% \mathrm{~A} / 95 \% \mathrm{~B}$ for 3 minutes followed by a gradient to $80 \% \mathrm{~A} / 5 \% \mathrm{~B}$ over 9 minutes which was kept for 3 minutes followed by a gradient to $95 \% \mathrm{~A} / 5 \%$ B over 25 minutes followed by 5 minutes at $95 \% \mathrm{~A} / 5 \% \mathrm{~B}$. This was followed by a 
gradient to $5 \% \mathrm{~A} / 95 \% \mathrm{~B}$ over 1 minute followed by 4 minutes at $5 \% \mathrm{~A} / 95 \% \mathrm{~B}$ at a flow rate of $1.0 \mathrm{~mL} \cdot \mathrm{min}-1$. HPLC analysis was used to determine $1-\mathrm{G}$ and $1-\mathrm{S}$ conversion, 7-G, 4-G, 5-G and 5-S according to the calibration versus 1,2,4,5 tetramethylbenzene, which was used as the internal standard.

Classical Molecular Dynamics Simulations Details. All the molecular dynamics (MD) simulations were performed with the Amsterdam Density Functional (ADF)/ReaxFF ${ }^{3}$. The force field was appropriately developed for this kind of solutes and tested in earlier studies. ${ }^{4} \mathrm{~A}$ minimum energy conformer of the solute was obtained after a conformational search carried out through the balloon software. ${ }^{5,6}$ Around 200 conformers were identified and then energy minimized at the DFT M06-2X/6-31G(d) level using the Gaussian 09 package $^{7}$. After organizing the collected data into families, the minimum energy structure was selected and used for the subsequent MD simulations. Ten 1-G molecules were inserted in a simulation box containing 502 DMC, 54 EG, and 47 sulphuric acid molecules (7313 atoms in all - Figure S1). Then, another configuration where the EG molecules were not present was created to comprehend how the stabilizer influenced the dynamics of the solute. Both configurations were minimized and equilibrated, first, in the NVT and then in the NPT ensemble at the experimental temperature $(\mathrm{T}=413 \mathrm{~K})$ for about one ns. The simulation box was approximately $41 \times 47 \times 46 \AA^{3}$, and periodic boundary conditions were applied in all directions. Subsequently, the production dynamics were performed in the NPT ensemble for about five ns, and the system structures were collected during the last nanosecond of the trajectories saving the coordinates every picosecond.

Temperature and pressure were controlled through the Berendsen's thermostat and barostat ${ }^{8}$ with relaxation constants of 0.1 ps. The time step was set to 0.20 fs. During this stage, reactivity was switched off to reduce the computational cost and maximize the sampling of promising configurations that could be good starting points (where the different actors were at interacting distances) for the reactive dynamics and subsequent quantum chemistry calculations.

Indeed, we were interested in disclosing the characteristic reactions of the solute, its fragmentation, and, eventually, self-aggregation. Thus, the analysis of the sampled data was focused on the location and orientations of the catalyst and stabilizer relative to the solute molecules and their competition with the solvent.

The examined descriptors were mainly atom-atom radial distribution functions (RDFs) and location probabilities of the various species. Visual inspection of the sampled coordinates was also fundamental to understand the solution scenarios and have an idea of the possible intermolecular interactions.

Molecular clusters (Figure S1b) containing one 1-G molecule and its nearest neighbors, namely one $\mathrm{H}_{2} \mathrm{SO}_{4}$ molecule, one EG molecule, and fifty DMC molecules, were extracted and used for the subsequent reactive MD simulations. Here, the purpose was primarily the generation of possible reaction paths in solution for the QC NEB calculations, where the system was reduced further to solute, catalyst, and stabilizer. This sequence of events was a sort of progressive refinement to identify transition paths and the corresponding energy barriers between given initial and final states (determined in the complex environment). Short reactive MDs were performed with specific distance restraints to induce the various reaction steps. Being a sort of explorative preliminary data will not be discussed in the manuscript. Possible reactant and product geometries from the simulations were then employed as starting structures of the NEB reaction paths. 
Quantum Chemistry NEB Simulations. All DFT calculations were carried out with QE using the plane waves UltraSoft (US) pseudopotentials ${ }^{9}$ and the Perdew-Burke-Ernzerhof (PBE) functional. The energy cutoffs for the wave function and charge density and potential were 40 Ry and $400 \mathrm{Ry}$, respectively. Single-particle wave functions were calculated through Gaussian smearing of about $0.002 \mathrm{Ry}$, and all the calculations were spin-unpolarized. Brillouin zone sampling was restricted to the gamma point. The Grimme-D2 method, which accounts for dispersion forces by correcting the DFT-derived energy, "a posteriori" for the dispersion effects ${ }^{10,11}$ was employed in all the calculations.

The NEB calculations were performed to determine the minimum energy paths (MEP), and the saddle states between the relaxed initial configurations of the reactants and products along the reaction coordinate. The energies barriers were estimated considering 25 intermediate images between the local minima.

A zip file containing all the NEB structures of the main mechanisms included in the manuscript (main text), namely step1, step2, and step3 is added as additional file. All the computational material, namely optimized DFT structures, MD trajectories, simulations control files, parameters, etc., are available from the authors upon reasonable request. 


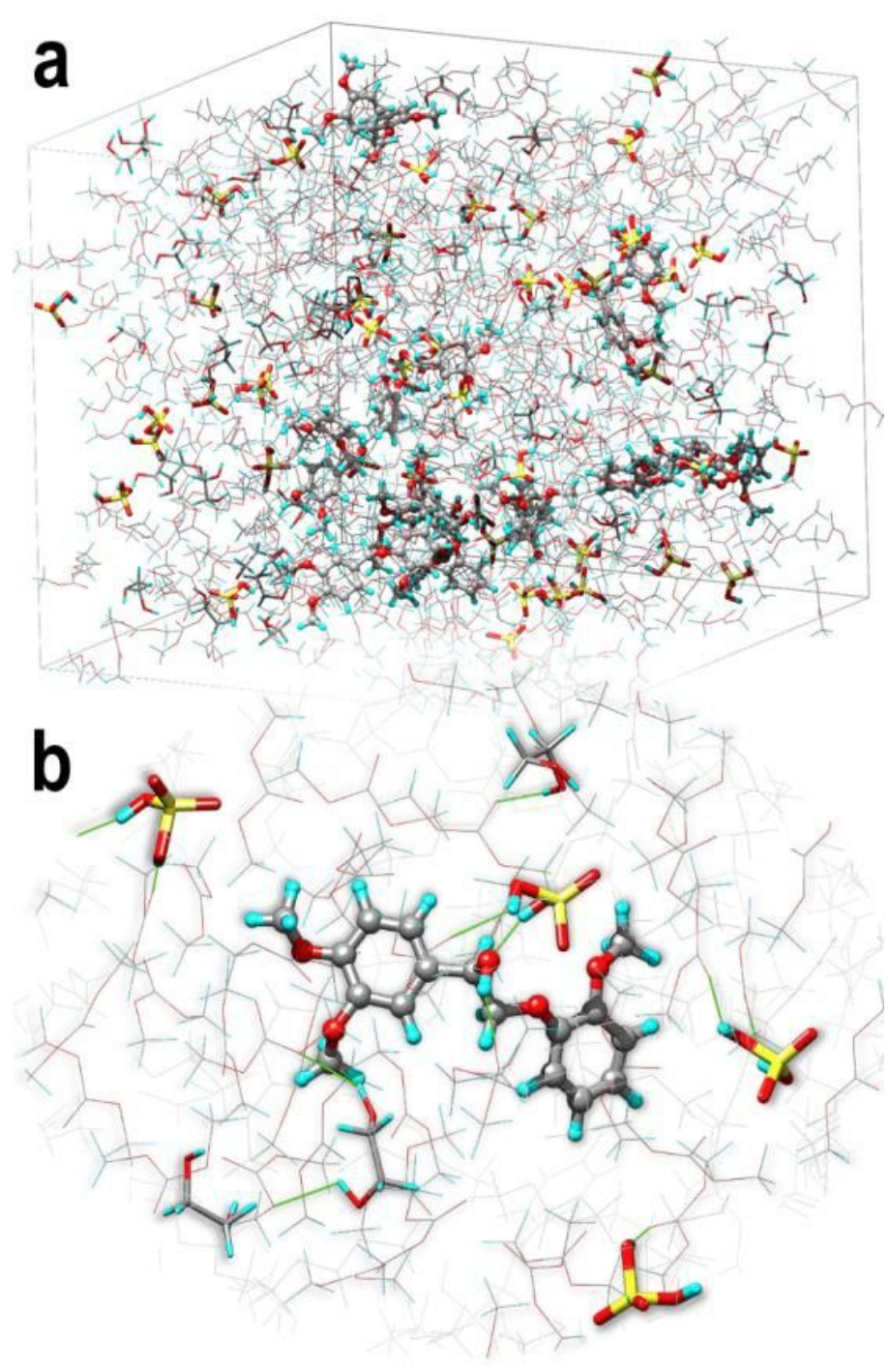

Figure S1. Representative configuration extracted from the molecular dynamics simulations of 1$\mathrm{G}$ in a DMC solution containing $\mathrm{H}_{2} \mathrm{SO}_{4}$ and $\mathrm{EG}$ molecules. a) Simulation box showing isolated and clustered solute structures surrounded by the catalyst and stabilizer molecules. b) Extracted subset where one 1-G molecule is in contact with one molecule of the catalyst and one molecule of the stabilizer and is surrounded by 50 solvent molecules. S, O, C, H atoms are yellow, red, grey and cyan, respectively. 


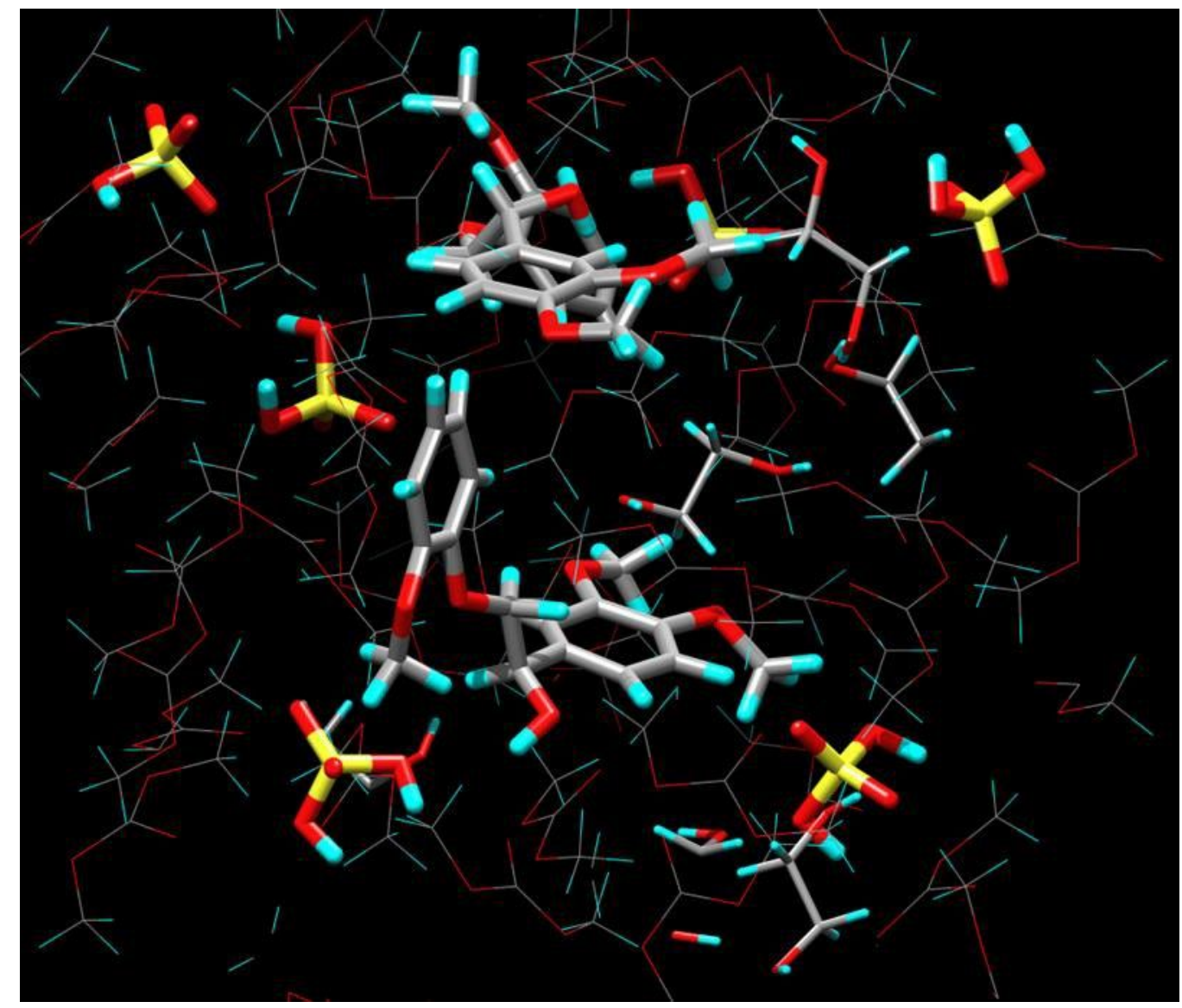

Figure S2. Representative configuration extracted from the molecular dynamics simulations of 1$\mathrm{G}$ in a DMC solution containing $\mathrm{H}_{2} \mathrm{SO}_{4}$ and $\mathrm{EG}$ molecules showing two solute molecules with perpendicular orientations of the rings. S, O, C, H atoms are yellow, red, grey and cyan, respectively.
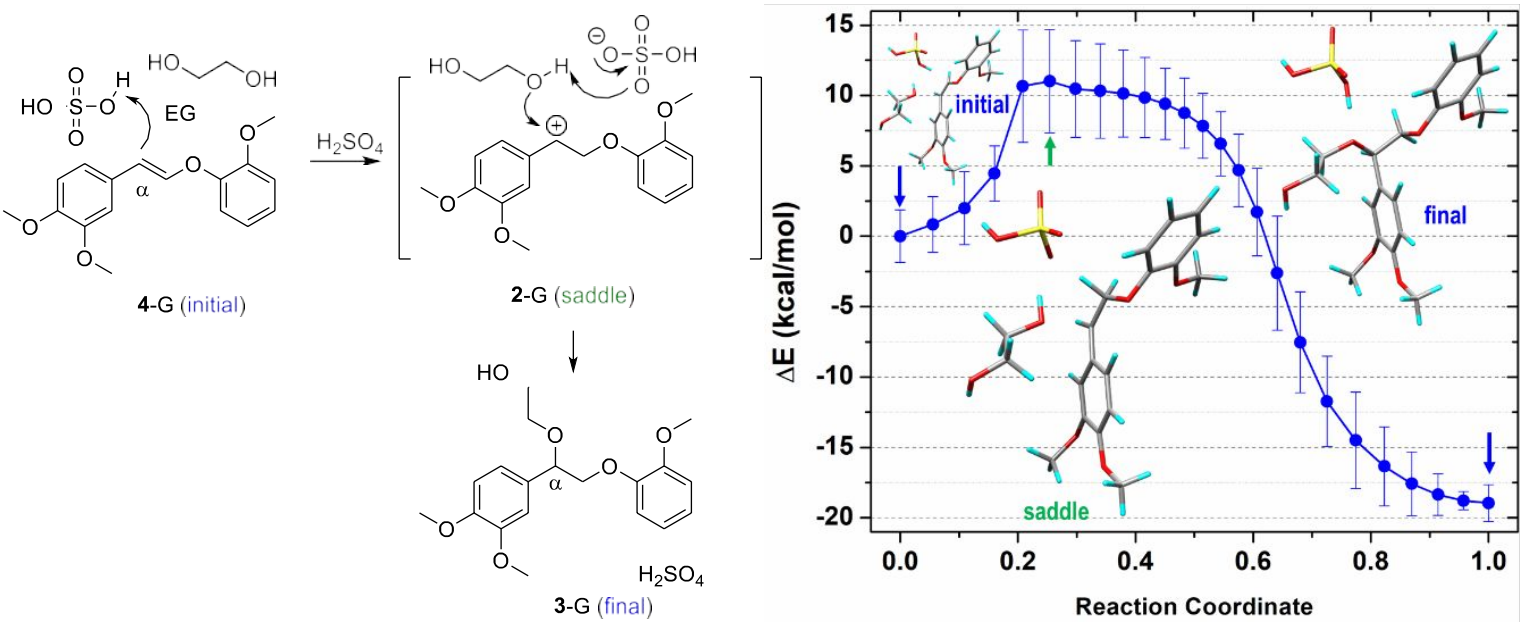

Figure S3. Minimum energy path and molecular structures of the reaction mechanisms depicting the formation of $3-\mathrm{G}$ from $4-\mathrm{G}$ 

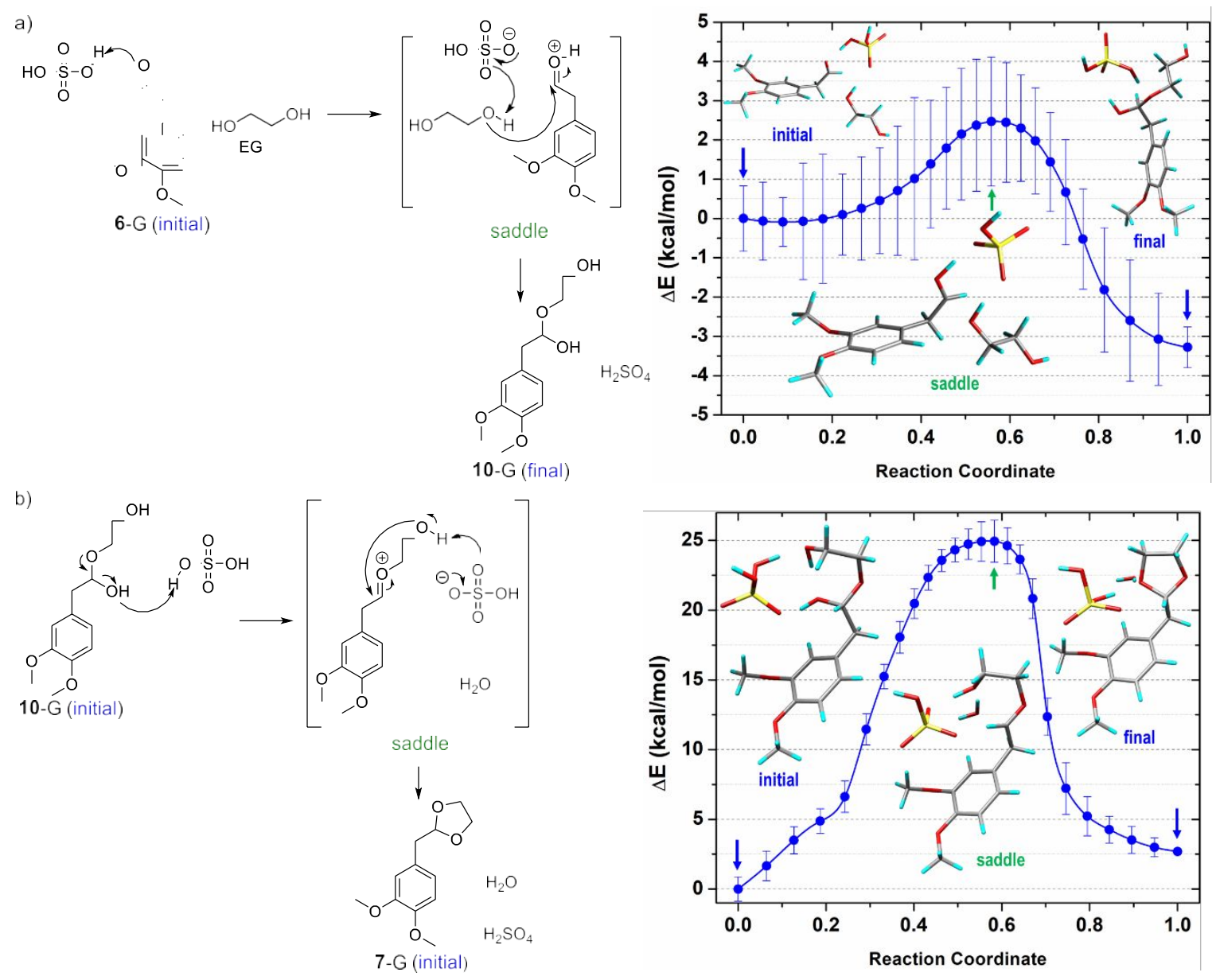

Figure S4. Minimum energy path and molecular structures of the reaction mechanisms depicting a) the formation of an intermediate 10-G starting from 6-G and EG; b) the formation of 7-G and water starting from $\mathbf{1 0}-\mathrm{G}$. 


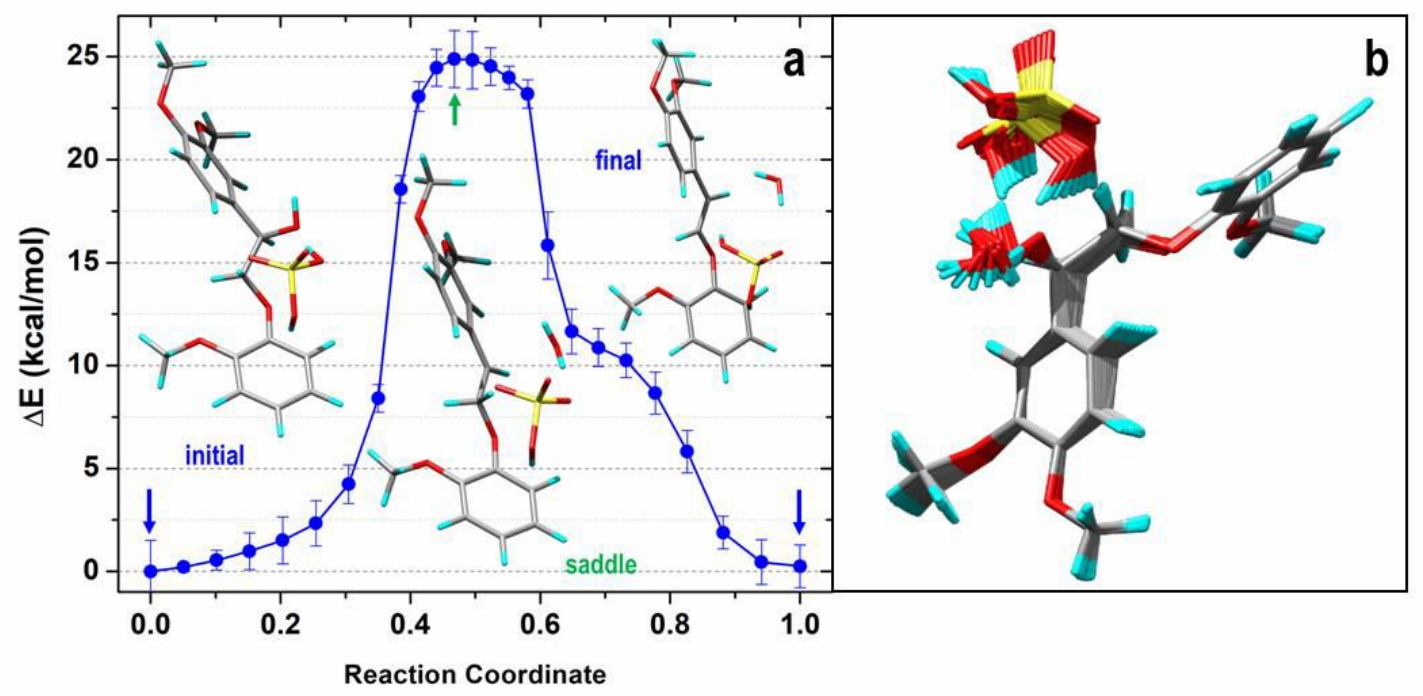

Figure S5. a) Minimum energy path and molecular structures of the reaction mechanism depicting the formation of 4-G from 1-G .b) Superimposed molecular configurations sampled along the reaction pathway obtained with the NEB approach. 

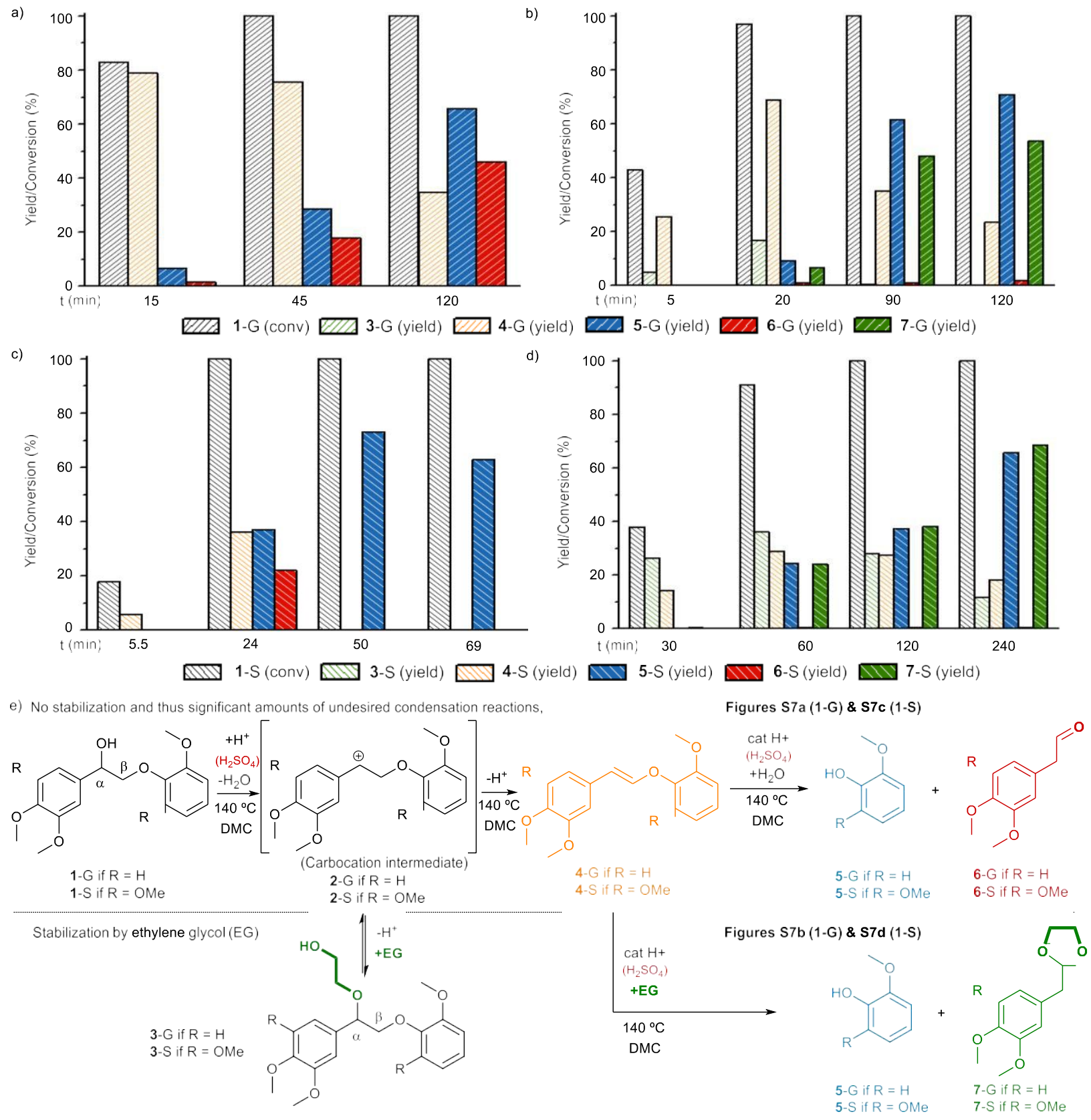

Figure S6. Acidolysis reaction profiles of a) 1-G no EG (path 1; b) 1-G with EG (path 2); c) 1-S no EG (path 1); d) 1-S in path 2 (with EG) as determined by HPLC/GC(FID). Reaction conditions: substrate (1-G or $1-\mathrm{S}, 1 \mathrm{eq}) 0.016 \mathrm{mmol} / \mathrm{mL}$ in dimethyl carbonate (DMC), internal standard (1,2,4,5-tetramethylbenzene, 1.7 eq), $\mathrm{H}_{2} \mathrm{SO}_{4}\left(2 \mathrm{~mol} \%\right.$ to substrate), $140{ }^{\circ} \mathrm{C}$ and for b) and d) ethylene glycol (EG, 4 equivalents), atmosphere: air.

Supplementary note: the yield of 6-G in path 1 and 7-G in path 2 (Figure S7a and S7b) were found to be comparable under these conditions ( $46 \%$ after 2 hours, Figure S7a and S7b) and lower than 5-G (66\% for pathway $1,71 \%$ for pathway 2 after 2 hours). It has to be noted that 3,4dimethoxybenzaldehyde was observed in these cases $(6 \%$ for path 1 and $12 \%$ for path 2 after 2 
hours) to account for the mass balance, indicating possible sulfuric acid-catalyzed oxidation of 6$\mathrm{G}$ and 7-G (air atmosphere was used in these cases to perform the experiments). ${ }^{12}$

\begin{tabular}{|c|c|c|c|c|c|c|c|c|}
\hline Compound & $\begin{array}{c}\text { EG } \\
\text { (eq.) }\end{array}$ & $\begin{array}{c}\text { Time } \\
\text { (h) }\end{array}$ & $\begin{array}{c}\text { 1-G or } 1-S \\
\text { conversion } \\
(\mathrm{mol} \%)\end{array}$ & $\begin{array}{c}\text { Yield } \\
\text { 7-G or } \\
7-S \\
(\mathrm{~mol} \%) \\
\end{array}$ & $\begin{array}{l}\text { Yield 3-G or } \\
\text { 3-S (mol\%) }\end{array}$ & $\begin{array}{c}\text { Yield 4-G } \\
\text { or 4-S } \\
(\operatorname{mol} \%)\end{array}$ & $\begin{array}{c}\text { Yield 5- } \\
\text { G or 5- } \\
\text { S } \\
(\mathrm{mol} \%) \\
\end{array}$ & $\begin{array}{c}\text { Yield 6-G } \\
\text { or 6-S } \\
(\mathrm{mol} \%)\end{array}$ \\
\hline $1-G$ & 0 & 4 & - & - & - & - & - & - \\
\hline 1-G & 4 & 4 & - & - & - & - & - & - \\
\hline 1-G[a] & 0 & 4 & - & - & - & - & - & - \\
\hline 1-G[a] & 4 & 4 & - & - & - & - & - & - \\
\hline $1-G^{[a, b]}$ & 0 & 4 & 6 & - & - & 4 & 1 & - \\
\hline $1-S$ & 0 & 24 & - & - & - & - & - & - \\
\hline $1-S$ & 4 & 24 & - & - & - & - & - & - \\
\hline $1-S^{[a]}$ & 0 & 24 & - & - & - & - & - & - \\
\hline $1-\mathrm{S}^{[\mathrm{a}]}$ & 4 & 24 & - & - & - & - & - & - \\
\hline $1-S^{[a, b]}$ & 0 & 24 & 14 & - & - & 10 & 2 & - \\
\hline
\end{tabular}

Table S1. Acidolysis reaction of model compound 1-G and 1-S using $\mathrm{HCl}$ (aqueous $37 \%$ ) as catalyst. Reaction conditions: substrate (1 eq, $0.016 \mathrm{mmol} / \mathrm{mL})$, Internal standard $(1,2,4,5$ tetramethylbenzene, $1.7 \mathrm{eq}), \mathrm{DMC}, \mathrm{HCl}(2 \mathrm{~mol} \%$ to substrate $), 140{ }^{\circ} \mathrm{C}$; [a] $\mathrm{HCl}$ in dioxane $4 \mathrm{M}$ [b] $\mathrm{HCl}$ was used in $20 \mathrm{~mol} \%$ to substrate. 


\section{References}

(1) Dawange, M.; Galkin, M. V; Samec, J. S. M. Selective Aerobic Benzylic Alcohol Oxidation of Lignin Model Compounds : Route to Aryl Ketones. ChemCatChem 2015, 7, 401-404.

(2) Nichols, J. M.; Bishop, L. M.; Bergman, R. G.; Ellman, J. A. Catalytic C - O Bond Cleavage of 2-Aryloxy-1-Arylethanols and Its Application to the Depolymerization of Lignin-Related Polymers. J. Am. Chem. Soc. 2010, 10 (132), 12554-12555.

Baerends, E. J.; Ziegler, T.; Atkins, A. J.; Autschbach, J.; Baseggio, O.; Bashford, D.; Bérces, A.; Bickelhaupt, F. M.; Bo, C.; Boerrigter, P. M.; Cavallo, L.; Daul, C.; Chong, D. P.; Chulhai, D. V.; Deng, L.; Dickson, R. M.; Dieterich, J. M.; Ellis, D. E.; Faassen, M. van; Fan, L.; Fischer, T. H.; Förster, A.; Guerra, C. F.; Franchini, M.; Ghysels, A.; Giammona, A.; Gisbergen, S. J. A. van; Goez, A.; Götz, A. W.; Groeneveld, J. A.; Gritsenko, O. V.; Grüning, M.; Gusarov, S.; Harris, F. E.; Hoek, P. van den; Hu, Z.; Jacob, C. R.; Jacobsen, H.; Jensen, L.; Joubert, L.; Kaminski, J. W.; Kessel, G. van; König, C.; Kootstra, F.; Kovalenko, A.; Krykunov, M. V.; Lenthe, E. van; McCormack, D. A.; Michalak, A.; Mitoraj, M.; Morton, S. M.; Neugebauer, J.; Nicu, V. P.; Noodleman, L.; Osinga, V. P.; Patchkovskii, S.; Pavanello, M.; Peeples, C. A.; Philipsen, P. H. T.; Post, D.; Pye, C. C.; Ramanantoanina, H.; Ramos, P.; Ravenek, W.; Rodríguez, J. I.; Ros, P.; Rüger, R.; Schipper, P. R. T.; Schlüns, D.; Schoot, H. van; Schreckenbach, G.; Seldenthuis, J. S.; Seth, M.; J.G. Snijders, M. Solà, M. S.; Swart, M.; Swerhone, D.; Tognetti, V.; Velde, G. te; Vernooijs, P.; Versluis, L.; Visscher, L.; Visser, O.; Wang, F.; Wesolowski, T. A.; Wezenbeek, E. M. van; Wiesenekker, G.; Wolff, S. K.; Woo, T. K.; Yakovlev, A. L. ADF. adf 2019.3 ADF, SCM, Theor. Chem. Vrije Univ. Amsterdam, Netherlands, http//www.scm.com.

(4) Monti, S.; Srifa, P.; Kumaniaev, I.; Samec, J. S. M. ReaxFF Simulations of Lignin Fragmentation on a Palladium-Based Heterogeneous Catalyst in Methanol - Water Solution. J. Phys. Chem. Lett. 2018, 9, 5233-5239.

(5) Vainio, M. J.; Johnson, M. S. Generating Conformer Ensembles Using a Multiobjective Genetic Algorithm. J. Chem. Inf. Model. 2007, 47, 2462-2474.

(6) Puranen, J. S.; Vainio, M. J.; Johnson, M. S. Accurate Conformation-Dependent Molecular Electrostatic Potentials for High-Throughput In Silico Drug Discovery. J. Comput. Chem. 2010, 31, 1722-1732.

(7) Frisch, M. J.; Trucks, G. W.; Schlegel, H. B.; Scuseria, G. E.; Robb, M. A.; Cheeseman, J. R.; Scalmani, G.; Barone, V.; Mennucci, B.; Petersson, G. A.; Nakatsuji, H.; Caricato, M.; Li, X.; Hratchian, H. P.; Izmaylov, A. F.; Bloino, J.; Zheng, G.; Sonnenberg, J. L.; Hada, M.; Ehara, M.; Toyota, K.; Fukuda, R.; Hasegawa, J.; Ishida, M.; Nakajima, T.; Honda, Y.; Kitao, O.; Nakai, H.; Vreven, T.; Montgomery, J. A. J.; Peralta, P. E.; Ogliaro, F.; Bearpark, M.; Heyd, J. J.; Brothers, E.; Kudin, K. N.; Staroverov, V. N.; Kobayashi, R.; Normand,J.; Raghavachari, K.; Rendell, A.; Burant, J. C.; Iyengar, S. S.; Tomasi, J.; Cossi, M.; Rega, N.; Millam, N. J.; Klene, M.; Knox, J. E.; Cross, J. B.; Bakken, V.; Adamo, C.; Jaramillo, J.; Gomperts, R.; Stratmann, R. E.; Yazyev, O.; Austin, A. J.; Cammi, R.; Pomelli, C.; Ochterski, J. W.; Martin, R. L.; Morokuma, K.; Zakrzewski, V. G.; Voth, G. A.; Salvador, P.; Dannenberg, J. J.; Dapprich, S.; Daniels, A. D.; Farkas, O.; Ortiz, J. V.; Cioslowski, J.; Fox, D. . Gaussian 09. Gaussian 09, Gaussian, Inc.Wallingford, CT, 2009.

(8) Berendsen, H. J. C.; Postma, J. P. M.; van Gunsteren, W. F.; DiNola, A.; Haak, J. R. Molecular Dynamics with Coupling to an External Bath. J. Chem. Phys. 1984, 81, 3684- 
3690.

(9) Vanderbilt, D. Soft Self-Consistent Pseudopotentials in a Generalized Eigenvalue Formalism. Phys. Rev. B 1990, 41 (11), 7892-7895.

(10) Grimme, S. Semiempirical GGA-Type Density Functional Constructed with a Long-Range Dispersion Correction. J. Comput. Chem. 2006, 27, 1787-1799.

(11) Grimme, S. Accurate Description of van Der Waals Complexes by Density Functional Theory Including Empirical Corrections. J. Comput. Chem. 2004, 25, 1463-1473.

(12) Duchek, J.; Piercy, T. G.; Gilmet, J.; Hudlicky, T. Chemoenzymatic Total Synthesis of EntNeopinone and Formal Total Synthesis of Ent -Codeinone from $\beta$-Bromoethylbenzene. Can. J. Chem. 2011, 89 (6), 709-728. 